CDD: 153.4

\title{
INNATISMO Y CONTROL GENÉTICO
}

\author{
SERGIO DANIEL BARBERIS \\ Universidad de Buenos Aires - CONICET \\ BUENOS AIRES \\ ARGENTINA \\ sergiobarberis@gmail.com
}

Received: 21.05.2012; Revised: 10.09.2013; Accepted: 23.10.2013

Resumen: Mi objetivo en este artículo es defender una elucidación reduccionista parcial del concepto de lo innato en ciencias cognitivas. En primer lugar, especifico las condiciones mínimas para una elucidación de lo innato. En segundo lugar, presento los principales enfoques que se han adoptado en la discusión, es decir, las propuestas reduccionistas, autonomistas y escépticas. Luego de ofrecer argumentos versus el escepticismo y las propuestas autonomistas, presento en detalle lo que considero es una elucidación parcial de lo innato en términos de control genético, mostrando cómo un concepto de la biología del desarrollo puede ser provechosamente utilizado para elucidar el concepto de lo innato en ciencias cognitivas. Por último, explicito las ventajas filosóficas de mi propuesta.

Palabras clave: Innatismo. Ciencias cognitivas. Biología del desarrollo. Control genético. Redes genéticas regulatorias.

\begin{abstract}
The aim of the present paper is to defend a partial reductionist explication of the concept of innateness in cognitive science. Firstly, I specify a set of minimal conditions for the analysis of the innateness concept. Secondly, I present the main proposals in dispute, namely, the reductionist, autonomist and skeptical accounts of innateness. After criticizing both skeptical and autonomist positions, I develop a partial account of innateness as genetic control, showing how that concept from developmental biology could be used to explicate innateness in cognitive science. Finally, I mention some philosophical advantages of my proposal.
\end{abstract}

Keywords: Innateness. Cognitive sciences. Developmental biology. Genetic control. Gene regulatory networks.

Manuscrito - Rev. Int. Fil., Campinas, v. 36, n. 2, p. 263-310, jul.-dez. 2013. 


\section{De qué hablamos cuando hablamos de innatismo}

En la explicación del desarrollo y de la estructura interna de diversas capacidades psicológicas, una gran variedad de teorías en ciencias cognitivas postulan, de manera explícita, la existencia de estructuras innatas. Desde el punto de vista de la filosofía de las ciencias cognitivas, son varios los aspectos de este hecho que resultan interesantes. En primer lugar, es importante destacar la diversidad de dominios respecto de los cuales se ha adoptado esta estrategia de explicación. Así, se han defendido hipótesis nativistas respecto del lenguaje (Chomsky 1975, 1980, 2005; Pinker 1994), ciertos principios del procesamiento visual (Marr 1982), la competencia matemática (Lipton y Spelke 2003), la física de sentido común (Spelke 1990), la biología de sentido común (Keil 1989), la psicología folk (Scholl y Leslie 1999) y el sentido moral (Hauser 2006). En segundo lugar, es interesante destacar que la postulación de estructuras innatas no es un rasgo idiosincrásico de las teorías nativistas, sino que muchas teorías que se ubican en el polo antinativista o empirista del continuum aceptan el carácter innato de algunas estructuras cognitivas. ${ }^{1}$ Aun el más acérrimo empirista psicológico estaría dispuesto a defender el carácter innato de ciertos mecanismos de aprendizaje de dominio general, o de dominio relevante, como los mecanismos de asociación o de inferencia estadística (Cowie 1999). Por último, cabe destacar la variedad de tipos

${ }^{1}$ Conviene aclarar desde el inicio que no reconstruyo el estado del debate en ciencias cognitivas como constando sólo de dos opciones teóricas dicotómicas, a saber: que una determinada estructura cognitiva $C$ es, o bien innata, o bien aprendida. Existe toda una variedad de posiciones intermedias en el debate naturaleza/crianza, i. e. enfoques psicológicos que aceptan la existencia de mecanismos innatos de adquisición que, si bien no son específicos de determinados dominios cognitivos, pueden "especializarse" en determinada función dependiendo de las contingencias en el curso del desarrollo (véase el enfoque neoconstructivista defendido por Karmiloff-Smith 1998).

Manuscrito - Rev. Int. Fil., Campinas, v. 36, n. 2, p. 263-310, jul.-dez. 2013. 
de estructuras cognitivas respecto de las cuales se han defendido hipótesis nativistas. Así, los científicos hablan acerca del carácter innato de representaciones mentales, creencias, teorías, conceptos, módulos, cuerpos de conocimiento, mecanismos de aprendizaje de dominio específico o de dominio general, sesgos atencionales, etc.

Todos estos aspectos de la estrategia nativista de explicación están relacionados con la cuestión filosófica de la que me ocupo en este artículo, a la que llamaré "la cuestión del innatismo" y que es la siguiente: ¿Es legítimo el uso del concepto de lo innato en ciencias cognitivas? La mayoría de las respuestas filosóficas a esta pregunta toman la forma de elaboradas respuestas a esta otra pregunta, íntimamente vinculada con la primera: ¿Cómo deben entenderse las afirmaciones de los científicos cognitivos acerca del carácter innato de ciertas estructuras cognitivas?

Según mi lectura del estado del debate, pueden distinguirse tres grandes familias de propuestas respecto de la cuestión del innatismo: las propuestas reduccionistas o biologicistas, las propuestas autonomistas y las propuestas escépticas. Aquí sólo esbozaré los lineamientos generales, pues la discusión de algunas de las propuestas que pertenecen a estas familias corresponde a las secciones siguientes.

En primer lugar, las propuestas reduccionistas consideran que es posible legitimar el uso del concepto de lo innato en ciencias cognitivas mediante una elucidación en términos de algún otro concepto específico perteneciente a la biología del desarrollo (Sober 1998, Ariew 1999, 2006). En este sentido, recogen una intuición bastante difundida entre los científicos cognitivos según la cual el carácter innato de una estructura debe radicar en alguna propiedad o conjunto de propiedades biológicas bien comprendidas (Godfrey-Smith 2007, p. 56).

Quienes sostienen propuestas autonomistas en cambio, consideran que es posible legitimar el uso del concepto de lo innato en ciencias cognitivas sin necesidad de comprometerse con que el 
concepto refiere a una clase natural específica de la biología del desarrollo. En este sentido, sería posible elucidar el concepto de lo innato puertas adentro de las ciencias cognitivas, sin necesidad de reducirlo a algún concepto biológico (Cowie 1999; Samuels 2002, 2007). La defensa de una propuesta de esta clase permitiría evitar una merma en la autonomía de la psicología cognitiva: en última instancia, resultaría deseable, según estos autores, que las modificaciones (radicales o no) en el repertorio conceptual de las ciencias básicas no afecten la legitimidad de los conceptos psicológicos.

Por último, según las propuestas escépticas, aun cuando el debate entre nativistas y empiristas sea sustancial, resulta sumamente confuso e improductivo (como mínimo: imprudente) plantearlo en términos de una dicotomía entre lo innato y lo aprendido (Griffiths 2002; Mameli y Bateson 2006). La razón detrás de esta prudencia está relacionada con la sospecha del carácter confuso del concepto de lo innato. Autores como Griffiths sostienen que la concepción científica de lo innato no es más que la exportación al (o la supervivencia en el) discurso científico de intuiciones esencialistas de sentido común acerca de los organismos vivos. Los psicólogos cognitivos estarían atrapados en la red de una distinción de sentido común entre "lo esencial" y "lo accesorio" respecto de un organismo o especie y, de este modo, la utilización del concepto de lo innato tendría como finalidad no tanto el desarrollo de una mejor comprensión de los fenómenos estudiados como la preservación de intuiciones acerca de una "naturaleza de la especie" y de una naturaleza humana, en particular (Griffiths 2002).

En este artículo me propongo desarrollar una elucidación reduccionista parcial del concepto de lo innato en ciencias cognitivas. Para lograr ese objetivo ofrezco, en primer lugar, algunas precisiones acerca de cuáles son los requisitos o las condiciones mínimas que una elucidación de lo innato debe satisfacer para resultar aceptable (sección 2). A la luz de tales requisitos, paso a ocuparme de las propuestas escépticas acerca del innatismo y brindo razones para rechazar el 
argumento de la confusión conceptual en el que se basan (sección 3). Asimismo analizo uno de los principales enfoques autonomistas, el primitivismo psicológico, y argumento que dicho enfoque es incompleto en la medida en que no elucida la noción (biológica) de plan de desarrollo normal de un organismo (sección 4). En la sección principal del artículo, presento en detalle lo que considero es una elucidación parcial de lo innato en términos del control genético sobre el desarrollo, recogiendo las principales virtudes del enfoque de lo innato como canalización ambiental (sección 5). Por último, respondo algunas de las objeciones que podrían plantearse a mi propuesta (sección 6).

2. Condiciones mínimas que una elucidación de lo innato debe satisfacer

Si bien no existe un consenso pleno al respecto en la bibliografía filosófica, existen notables antecedentes que pueden ser tenidos en cuenta en la explicitación de los requisitos para una elucidación de lo innato. En este sentido, retomo parcialmente algunas de las condiciones de adecuación que Ariew (1999), Samuels (2002) y otros autores establecen para la cuestión del innatismo en ciencias cognitivas. La primera condición es bastante obvia en sus lineamientos generales y afirma lo siguiente:

Condición de adecuación extensional: una elucidación adecuada de lo innato debe permitir incluir, en la extensión del concepto, las estructuras (no sólo cognitivas) consideradas como aplicaciones empíricas pretendidas de las teorías nativistas.

La idea general de esta condición es que una elucidación adecuada debe permitir recoger como innatos aquellos rasgos a los 
cuales los nativistas pretenden aplicar el concepto. ${ }^{2}$ Por ejemplo, si una elucidación de lo innato arrojase como resultado que los principios de la Gramática Universal (GU) postulados por el Modelo de Principios y Parámetros (Chomsky 1988) o los módulos cognitivos tal como los entiende Fodor (1983) no son estructuras innatas, entonces dicha elucidación violaría claramente la condición de adecuación extensional. ${ }^{3}$

Resulta interesante la relación entre la condición de adecuación extensional y los ejemplares no cognitivos de lo innato provenientes de la biología del desarrollo. Considérense, por ejemplo, el desarrollo del hígado en humanos y otros animales, o el desarrollo del segmento torácico de la Drosophila. ¿Deben tenerse en cuenta este tipo de ejemplares paradigmáticos al desarrollar una elucidación de lo innato en ciencias cognitivas? Autores como Samuels (2002) y Khalidi (2007) prefieren permanecer neutrales respecto de los usos del concepto de 10 innato por fuera de las ciencias cognitivas. Otros autores, como Ariew

2 Por supuesto, esta condición presupone que existe una noción de lo innato que es común a las principales teorías nativistas en ciencias cognitivas. Si este presupuesto resultase falso, entonces estaría dispuesto a limitar mi elucidación a las teorías que mencioné en la sección 1.

3 Podría objetarse que es (al menos) lógicamente posible que un científico defienda que una cierta estructura $a$ posea la propiedad $p$ porque se desconoce, en ese momento de la investigación, que a posee algunas otras propiedades distintas de $p$ que contradicen la atribución de $p$ a dicha estructura. Podría ser el caso, entonces, que una elucidación plenamente adecuada de lo innato no recoja los principios de la GU de la teoría chomskiana ni ninguna de las otras aplicaciones pretendidas actuales de las diferentes teorías nativistas, pues estas últimas podrían estar omitiendo propiedades relevantes (actualmente desconocidas) para la atribución del concepto. Por supuesto, debe admitirse esta posibilidad, pero, lamentablemente, no nos queda sino tomar riesgos y partir de las mejores teorías nativistas disponibles para encarar la tarea de elucidación de lo innato pues, ¿por dónde más podríamos comenzar? Ciertamente, se corre cierto riesgo de circularidad aquí, pero considero que se trata de una circularidad virtuosa, a saber: aquella que es esperable entre los análisis conceptuales y las teorías científicas disponibles.

Manuscrito - Rev. Int. Fil., Campinas, v. 36, n. 2, p. 263-310, jul.-dez. 2013. 
(1999), Collins (2005) y Mameli y Bateson (2006) sostienen, en cambio, que una elucidación adecuada de lo innato debe incorporar en la extensión del concepto no sólo estructuras cognitivas, sino también, y fundamentalmente, estructuras biológicas en general. La disputa pone en juego convicciones metateóricas fundamentales. Mis propias convicciones acuerdan con una interpretación amplia del requisito de adecuación extensional, de modo tal que incluya los casos provenientes de la biología. La principal razón a favor de esta convicción es que muchos referentes del nativismo en ciencias cognitivas vinculan explícitamente el concepto de lo innato en sus teorías cognitivas con los usos del concepto (o de otros conceptos estrechamente vinculados) en ciencias biológicas más básicas, como la biología del desarrollo o la etología (Chomsky 1980, 1995, 2005; Fodor 1998a). ${ }^{4}$

La segunda condición de adecuación que propongo es la siguiente:

Condición de relevancia evidencial: Una elucidación adecuada de 10 innato debe ser tal que los fenómenos empíricos que comúnmente se señalan como evidencia del carácter innato de una estructura resulten relevantes para establecer las tesis nativistas.

${ }^{4}$ Es importante aclarar que no estoy afirmando que el concepto de lo innato se utilice en todos los campos de la biología. Claramente, el concepto ha sido utilizado en campos tales como la inmunología (Jerne 1984), la biología del desarrollo (Gottlieb 1991, Marcus 2005) y la etología (Lorenz 1965, Gould y Marler 1981, Cheney y Seyfarth 2007). Los teóricos nativistas más importantes han vinculado, en virtud de la aceptación de compromisos ampliamente naturalistas, las atribuciones de innatismo a componentes de la mente/cerebro con las atribuciones de innatismo a estructuras biológicas pero no cognitivas tales como los órganos corporales, los caracteres sexuales secundarios, las enfermedades hereditarias, etc. No veo por qué la condición de adecuación extensional debería excluir, sin mayor discusión, dichas vinculaciones.

Manuscrito - Rev. Int. Fil., Campinas, v. 36, n. 2, p. 263-310, jul.-dez. 2013. 
Esta condición pretende recuperar el espíritu de la "restricción argumental" propuesta por Samuels (2002). Según este autor, a igualdad de condiciones, deberíamos preferir un enfoque acerca del innatismo para el cual los argumentos centrales esgrimidos por los nativistas resulten, como mínimo, relevantes para la fundamentación de las hipótesis que pretenden defender. ${ }^{5}$ En otras palabras, no sólo debemos exigir que una elucidación adecuada permita recoger determinadas estructuras como innatas -aquellas que los científicos cognitivos acuerdan como tales- sino que además debemos exigir que torne relevantes (aunque no necesariamente decisivas o demostrativas) a las razones por las cuales los científicos las consideran innatas. A diferencia de la restricción argumental de Samuels (2002), la condición de relevancia evidencial no reconstruye tales razones como "argumentos" a favor del carácter innato de estructuras cognitivas, sino como fuentes de evidencia que pueden ofrecer cierto grado de confirmación o de apoyo inductivo a las hipótesis nativistas.

¿Cuáles son las fuentes de evidencia que una elucidación adecuada debería recoger como relevantes para el establecimiento de hipótesis nativistas? Puesto que estas fuentes de evidencia pueden utilizarse para evaluar diversas propuestas acerca de la cuestión del innatismo, conviene tener en mente dos advertencias. En primer lugar, los fenómenos empíricos a considerar deben aparecer mencionados de manera recurrente por los propios científicos cognitivos en defensa de sus hipótesis nativistas. Así, tomaré como hilo conductor las fuentes de evidencia que comúnmente se consideran relevantes en los debates entre nativistas y empiristas en dominios tales como el lenguaje, la competencia matemática, mindreading y el reconocimiento de rostros,

5 "Si bien Chomsky, Fodor, Spelke y otros nativistas en ciencias cognitivas pueden estar equivocados, seguramente no están tan desesperadamente confundidos en sus argumentos como para que sus argumentos no sean siquiera prima facie relevantes para establecer las tesis que se proponen defender." (Samuels 2002, p. 237)

Manuscrito - Rev. Int. Fil., Campinas, v. 36, n. 2, p. 263-310, jul.-dez. 2013. 
entre otros. En segundo lugar, no debe cometerse, en la medida de lo posible, una petición de principio en contra de las elucidaciones filosóficas de lo innato que se encuentran actualmente en debate. En este sentido, conviene atenerse principalmente a aquellas fuentes de evidencia que los filósofos del innatismo hayan tomado como guía, de manera más o menos explícita, en sus elucidaciones. Teniendo en cuenta estas salvedades, la siguiente lista (no exhaustiva) de fenómenos puede resultar conducente:

(1) El desarrollo de un output complejo en condiciones de input empobrecido. Claramente, éste es uno de los principales fenómenos empíricos que puede ofrecerse como evidencia a favor de la presencia de factores innatos determinantes en el desarrollo, y es el que está a la base de los argumentos de la pobreza del estímulo (APE) de Chomsky $(1975,1980)$ y de otros científicos cognitivos. Por su parte, filósofos como Ariew (1999), Samuels (2002), Collins (2005) y Khalidi (2007) coinciden en señalar la necesidad de atender a los argumentos de la pobreza del estímulo en una elucidación de lo innato. Según este tipo de argumentos, el hecho de que el estado final de una estructura cognitiva sea demasiado rico y complejo en comparación con la información disponible en el entorno de adquisición, otorga apoyo evidencial (no demostrativo) a la hipótesis de que esa estructura es innata. En el caso del lenguaje, el argumento de la pobreza del estímulo chomskiano afirma que la brecha que existe entre la competencia lingüística madura adquirida por los niños al cabo del proceso de adquisición y la pobreza del estímulo lingüístico al que están expuestos durante tal proceso no puede llenarse postulando mecanismos empiristas de aprendizaje, por lo que es necesario postular principios innatos y específicos del dominio lingüístico que guíen al niño a través del espacio lógico de hipótesis gramaticales posibles (Laurence y Margolis 2001).

(2) El desarrollo relativamente temprano. El hecho de que los niños presenten ciertas capacidades complejas -como la de distinguir entre diferentes cantidades y clases de formas geométricas (Carey y Spelke 
1992) - que se explican mediante la postulación de ciertas estructuras cognitivas, unido al hecho de que estas capacidades emergen en estadios sumamente tempranos del desarrollo, constituye evidencia importante versus la posibilidad de que tales estructuras hayan sido aprendidas y, por tanto, constituye evidencia indirecta de que tales estructuras son innatas. Samuels (2002) recoge esta fuente de evidencia como el "argumento del desarrollo temprano" a favor del nativismo y la considera una condición relevante para elucidar el innatismo. La principal diferencia con la primera fuente de evidencia radica en que el acento no está puesto en la pobreza relativa de la información ambiental, sino en la precocidad relativa de la aparición de la estructura en cuestión.

(3) La existencia de un período crítico de adquisición. Generalmente, se considera que el hecho de que una estructura sólo pueda adquirirse o desarrollarse normalmente durante una determinada "ventana temporal" en el curso de la ontogénesis constituye una evidencia a favor del carácter innato de esa estructura. Si un organismo no recibe el estímulo disparador apropiado durante el período crítico del desarrollo de una capacidad, se vuelve difícil o incluso imposible estimular el desarrollo de esa capacidad posteriormente en el curso del crecimiento. Este tipo de evidencia es especialmente enfatizado por Ariew (2006) y Mameli y Bateson (2006) en sus análisis del innatismo. En el caso del lenguaje, Lenneberg (1967) y Pinker (1994), entre otros, han defendido la idea de que la adquisición de la lengua materna se desarrolla de manera exitosa durante los primeros años de vida y que se torna más difícil con el tiempo hasta volverse prácticamente imposible luego de la pubertad.

(4) La invariancia ambiental. El hecho de que una estructura aparezca o se desarrolle en un amplio rango de entornos ofrece evidencia a favor del carácter innato de dicha estructura. Esta fuente de evidencia es enfatizada por Ariew (1999), Mameli y Bateson (2006) y Samuels (2007) en sus análisis del concepto de lo innato. Muchas veces 
esta propiedad se presenta, en la bibliografía psicológica, en términos del carácter pancultural de una estructura cognitiva, esto es: el hecho de que el rasgo en cuestión aparezca o se desarrolle en todas las culturas conocidas. En el caso del lenguaje, esta propiedad se manifiesta en el hecho de que todos los niños, en cualquier cultura en la que sean educados, logran adquirir el lenguaje de su comunidad. El carácter invariante respecto del entorno de un rasgo no constituye una prueba indiscutible del carácter innato del mismo: un rasgo puede desarrollarse en toda una gama de entornos debido a la presencia contingente del factor ambiental determinante de su desarrollo en cada uno de esos entornos, y no debido a una "necesidad biológica", que torne insensible su desarrollo respecto de los posibles factores ambientales. La inclusión de esta propiedad como condición de adecuación no exige que la propiedad brinde condiciones suficientes y mucho menos necesarias del innatismo de un rasgo, sino que lo único que se requiere es que el carácter invariante de un rasgo, en conjunto con el resto de la evidencia, pueda brindar apoyo inductivo al nativismo.

(5) La existencia de déficits del desarrollo especificos (correlacionados con alteraciones genéticas especificas). Este tipo de evidencia será crucial en el despliegue de mi argumentación, por lo que aquí sólo ofreceré una primera caracterización. La lógica del patrón explicativo asociado a este tipo de evidencia es la siguiente. Supóngase que se logra establecer la existencia de un déficit del desarrollo, específico de un dominio cognitivo, para cuya explicación se postula un daño selectivo en una estructura cognitiva determinada, llamémosla C. Supóngase también que ese déficit está fuertemente correlacionado con una alteración genética específica (por ejemplo, el déficit en cuestión presenta un patrón de herencia autosómico dominante). Si ese fuese el caso, estaríamos en presencia de una fuente de evidencia a favor del carácter innato de la estructura cognitiva $C$. En el caso del lenguaje, la apelación a este tipo de evidencia es relativamente reciente (Pinker 1994, Marcus y Fisher 2003, Marcus 2004), aunque no representa una novedad en los 
estudios biológicos del desarrollo cognitivo y conductual de organismos más simples como la Drosophila o los roedores (reseñados en Gehring 2005). El síndrome relevante en el caso del desarrollo del lenguaje es el "daño selectivo del lenguaje" (Specific Language Impairment, o SLI), un déficit cognitivo hereditario que presenta un patrón de herencia mendeliano (autosómico dominante) y que, al parecer, daña específicamente las habilidades gramaticales o morfológicas de los sujetos afectados (Gopnik 1990). Sumado a este patrón específico de daño cognitivo, parece ser el caso que, desde el punto de vista genético, una mutación en un único gen (FOXP2) es todo lo que se requiere para la manifestación del SLI (aun cuando, naturalmente, se necesita también de una contribución del ambiente). Estas consideraciones ofrecen evidencia positiva a favor de la hipótesis del carácter innato de un módulo de adquisición del lenguaje (Gopnik 1990, 1997; Gopnik y Crago 1991; Pinker 1994; Marcus y Fisher 2003). ${ }^{6}$

Conviene realizar una aclaración respecto de las fuentes de evidencia (1)-(5). Ninguna de ellas es una evidencia directa, indiscutible e irrevocable del carácter innato de una estructura o rasgo biológico. Cada una de ellas aporta apoyo confirmatorio prima facie a favor de hipótesis nativistas y, en la mayoría de los casos, sólo ofrecen una fundamentación plausible a favor de una hipótesis nativista en la medida en que se manifiestan en tándem. Ésta es la idea que pretenden

${ }^{6}$ Samuels (2002) no discute esta fuente de evidencia en su "restricción argumental". Sin embargo, hay buenas razones para pensar que la considera relevante para la cuestión del innatismo. Así, este autor afirma que una buena elucidación de lo innato no debe excluir la posibilidad de estructuras innatas que puedan dañarse selectivamente, pues se trata de una posibilidad genuina que es relevante para las ciencias cognitivas. De hecho, Samuels reseña las investigaciones de Leslie (cf. Scholl y Leslie 1999), quienes se proponen explicar de manera nativista los déficits de mindreading en los niños autistas mediante la postulación de un daño selectivo en un módulo innato de teoría de la mente. Para una reseña pormenorizada sobre las bases genéticas del autismo infantil, véase Geschwind (2011).

Manuscrito - Rev. Int. Fil., Campinas, v. 36, n. 2, p. 263-310, jul.-dez. 2013. 
recoger Mameli y Bateson (2006) cuando sugieren que las propiedades o síntomas de innatismo tienden a ocurrir conjuntamente, de tal manera que la presencia de uno de ellos es un indicador más o menos fiable de la presencia de algunos (o de todos) los otros síntomas de innatismo. En este sentido, no debe perderse de vista que, si bien separo los fenómenos de la pobreza del estímulo (1), el desarrollo temprano (2), la existencia de un período crítico de adquisición (3) y la invariancia ambiental (4) por motivos de claridad conceptual, estos fenómenos suelen presentarse en tándem en la bibliografía nativista, de tal manera que la pobreza del estímulo sólo es un índice confiable de un rasgo o estructura innata si se presenta crucialmente acompañada del desarrollo temprano, la invariancia ambiental y la existencia de un período crítico de adquisición (véase Crain y Pietroski 2001, Laurence y Margolis 2001 y Ezcurdia 2013).

En suma, considero que bastan la condición de adecuación extensional y la condición de relevancia evidencial, así caracterizadas, para encarar la evaluación de las propuestas filosóficas respecto de la cuestión del innatismo. Si una propuesta permite incluir en la extensión del concepto los casos paradigmáticos de innatismo propuestos por las teorías nativistas, y permite también que las principales fuentes de evidencia a favor del innatismo sean relevantes para establecer las hipótesis nativistas, entonces consideraré que esa propuesta es satisfactoria en tanto elucidación de lo innato en ciencias cognitivas.

3. Contra el escepticismo: el rechazo del argumento de la confusión conceptual

Comenzaré a esbozar una propuesta acerca de la cuestión del innatismo a través de la crítica a las propuestas escépticas. Según Griffiths (2002), el concepto de lo innato es una noción ilegítima que obstaculiza la comprensión científica del desarrollo cognitivo. El primer argumento de Griffiths a favor de esta tesis parte de una premisa según 
la cual nuestra biología esencialista de sentido común presupone que cada organismo posee una propiedad inobservable subyacente (su "naturaleza" o "esencia") que causa las propiedades observables propias de la especie a la que pertenece (Keil 1989). Desde esta perspectiva tipológica sobre las especies, las variaciones individuales son vistas como "desviaciones" respecto de un tipo ideal. Según Griffiths (2002, p. 83), la estrategia esencialista de explicación causal se condensa, en el caso de los seres humanos, en la noción de "naturaleza humana". Esta noción permite que la gente explique, en contextos cotidianos, diversos fenómenos: la universalidad de ciertos rasgos humanos (como la envidia o la ambición), la futilidad de la interferencia en el desarrollo de ciertas características y la idea de una finalidad o intencionalidad en el desarrollo humano. La segunda premisa de este argumento afirma que la idea de naturaleza humana refiere, en última instancia, al conjunto de aquellas características de los seres humanos que catalogaríamos como "innatas" desde un punto de vista precientífico. Si se afirma, siempre en el ámbito de lo cotidiano, que un rasgo determinado forma parte de la naturaleza humana, entonces es sensato pensar que se está afirmando que tal rasgo es innato y viceversa. Puesto que el concepto ordinario de lo innato es sinónimo de naturaleza bumana, y dado que este último no es más que la aplicación al caso humano del concepto folk esencialista de especie, Griffiths concluye que el concepto de lo innato es una expresión de esencialismo biológico. En ese caso, el concepto de lo innato es irremediablemente incompatible con la concepción darwiniana de las especies, pues "las especies no son tipos a los cuales los organismos individuales se conforman más o menos perfectamente, sino abstracciones a partir de pools de variaciones superpuestas que constituyen las poblaciones actuales" (Griffiths 2002, p. 78). La perspectiva nativista sobre el desarrollo humano es una forma solapada de esencialismo acerca de las especies y, por lo tanto, es incompatible con la perspectiva poblacional que adopta la biología moderna, al menos, desde Darwin. 
Mi objeción es que no está para nada claro que Griffiths haya logrado establecer el tipo de vínculo conceptual que su argumento necesita entre el concepto ordinario de lo innato y la perspectiva esencialista acerca de la naturaleza humana. Como reconoce el propio autor en varios pasajes (Griffiths 2002, p. 85), los conceptos de innatismo, instinto y naturaleza humana no son tan fácilmente asimilables. Desde un punto de vista intuitivo, estaríamos dispuestos a reconocer que un rasgo puede ser innato sin que, por eso mismo, ese rasgo forme parte de la naturaleza humana. Aun cuando todo rasgo "natural" es innato, no todo rasgo innato es "natural". Generalmente, de hecho, no consideramos que síndromes hereditarios tales como el autismo o la enfermedad de Huntington formen parte de la naturaleza humana, o que puedan ser considerados "instintivos", aun cuando puedan ser catalogados sensatamente como rasgos innatos. Por lo tanto, no todas las atribuciones de innatismo presuponen un compromiso esencialista acerca de la "naturaleza" de la especie.

De acuerdo a un segundo argumento de Griffiths (2002), el concepto de lo innato es ilegítimo porque es una noción fundamentalmente confusa. Este cargo de confusión debe entenderse en términos semánticos: el concepto estaría (al menos, parcialmente) constituido por una serie de rasgos conceptuales que no sólo serían independientes teóricamente, sino que, además, estarían empíricamente disociados. En particular, Griffiths (2002) señala los siguientes "sentidos" como componentes constitutivos del concepto de lo innato:

Adaptación: la estructura en cuestión tiene una explicación evolutiva en términos de selección natural.

Fijeza en el desarrollo o canalización: la estructura presenta un curso de desarrollo "difícil de cambiar", esto es, insensible a los factores del ambiente.

Invariancia: la estructura es compartida por todos los miembros de la especie (ya sea por ser pancultural o monomórfica). 
Claramente -continúa el argumento escéptico- estas tres propiedades, a las que llamaremos propiedades-i, son teórica y empíricamente independientes. Por ejemplo, en la medida en que la selección natural sólo "selecciona los resultados" del desarrollo, un rasgo puede constituir una adaptación y sin embargo depender de manera decisiva de la presencia de una amplia gama de factores ambientales para su desarrollo. Es el caso del comportamiento de captura del águila pescadora: dicho comportamiento constituye una adaptación darwiniana por excelencia; sin embargo, emerge como el producto de un largo y complicado proceso de imitación y aprendizaje (Mameli y Bateson 2006; Griffiths y Machery 2008). O, tal como mencioné en la sección 2, una estructura puede surgir de manera invariante en un amplio rango de entornos por otras razones que no tengan que ver con la insensibilidad a factores ambientales, sino con la sensibilidad a un factor ambiental contingentemente presente en cada uno de esos entornos de desarrollo (Ariew 1999). La noción de lo innato amalgama indistintamente diversas propiedades biológicas que deben ser cuidadosamente distinguidas.

En respuesta a este argumento de la confusión conceptual, seguiré la réplica de Samuels (2007). Aun cuando se le conceda a Griffiths que existe alguna relación entre el concepto de lo innato y las propiedades de invariancia ambiental, desarrollo canalizado e historia adaptativa, no hay buenas razones para pensar que esta relación deba ser de constitución conceptual. De hecho, existe una interpretación alternativa de las relaciones entre el concepto de lo innato y las propiedades-i. Según esta propuesta alternativa, el descubrimiento de que cierta estructura biológica posee alguna de las propiedades-i ofrece evidencia empírica a favor del innatismo de dicha estructura. Esta interpretación sencillamente bloquea el cargo de confusión conceptual, pues la existencia de varias líneas de evidencia, conceptual y empíricamente independientes entre sí, en apoyo a una tesis, es un lugar 
común de la práctica científica. Todas las observaciones filosóficas de Griffiths son compatibles con esta hipótesis alternativa, según la cual las propiedades-i sólo ofrecen evidencia a favor de hipótesis nativistas, sin ser constitutivas del significado del concepto de lo innato. Por lo tanto, parece que lo único que necesitamos para superar el escepticismo es desarrollar una elucidación de lo innato que muestre cómo las propiedades-i pueden resultar relevantes como fuentes de evidencia a favor del carácter innato de una estructura. Pero esto último equivale, en la práctica, a desarrollar una elucidación de lo innato que satisfaga, en mi terminología, el requisito de relevancia evidencial introducido en la sección 2 .

La formulación en términos del requisito de relevancia evidencial presenta ciertas ventajas respecto de la formulación en términos del conjunto de propiedades-i. En primer lugar, casi todos los participantes del debate coinciden en señalar que la propiedad de ser una adaptación evolutiva ofrece una evidencia muy débil, si alguna, a favor del carácter innato de un rasgo, por las razones expuestas en esta misma sección respecto de la dificultad de establecer relaciones (causales o de cualquier tipo) entre el hecho de que un rasgo sea una adaptación y las diferentes características que pueda presentar su ontogénesis (y que sean relevantes para la cuestión del innatismo) (Ariew 1999, Mameli y Bateson 2006). En segundo lugar, ningún participante del debate considera que la propiedad de poseer un desarrollo canalizado deba considerarse como una fuente de evidencia de lo innato más que como una caracterización misma de lo innato. De hecho, la idea de que un rasgo psicológico es innato en la medida en que su desarrollo está canalizado respecto del entorno constituye el núcleo de la propuesta reduccionista de Ariew (1999, 2006), que presento y defiendo (de alguna manera) en la sección 5. Por su parte, la invariancia ambiental está incluida entre los fenómenos empíricos contemplados por la condición de relevancia evidencial, junto con otro conjunto de fenómenos que el conjunto de propiedades-i no contempla, como los 
fenómenos de pobreza del estímulo, los períodos críticos de adquisición y la existencia de déficits hereditarios específicos. En conclusión, las fuentes de evidencia vinculadas a la condición de relevancia evidencial constituyen un conjunto mucho más completo y adecuado (si bien no exhaustivo) que aquel constituido por las propiedades-i.

\section{Contra las propuestas autonomistas}

Ahora bien, ¿hacia qué tipo de propiedad apuntan las diferentes fuentes de evidencia recogidas en la condición de relevancia evidencial? Es en relación a esta cuestión que los enfoques autonomistas acerca del innatismo exhiben sus mayores problemas. Para mostrar esto, me concentraré en una de las principales propuestas autonomistas disponibles, a saber: el primitivismo psicológico de Samuels (2002).

Siguiendo la interpretación de Mallon y Weinberg (2006), cabe distinguir entre dos variantes de la propuesta primitivista de Samuels. Según la variante metateórica del primitivismo, una estructura es innata si y sólo si es postulada por una teoría psicológica y su adquisición no puede explicarse, por principio, mediante los recursos conceptuales de ninguna teoría psicológica. La afirmación de que no hay teoría psicológica correcta que explique la adquisición de los rasgos innatos no es una aserción descriptiva relativa al estado actual de las ciencias cognitivas, sino que es una afirmación normativa, en el sentido de que no hay teoría psicológica alguna que deba ser descubierta al respecto. Tampoco quiere decir que la explicación de la adquisición de los rasgos primitivos sea un "misterio" para la imagen científica del mundo (tal como sugiere Cowie 1999). La idea es que, aun cuando se logre alcanzar una teoría psicológica completa, ésta no incluirá una descripción psicológica del proceso de adquisición de las estructuras que considere innatas. Tal proceso debe ser explicado, en principio, por alguna otra disciplina "más básica", tal como la neurobiología del desarrollo o la 
genética. Nótese que, en esta versión del primitivismo, la noción de "primitivo" relevante para trazar la distinción entre lo innato y lo no innato no refiere a una propiedad estructural - esto es, concerniente a la complejidad relativa de una estructura - sino a una propiedad explicativa o metateórica - es decir, concerniente al rol de un concepto como "ladrillo básico" de la teorización en psicología (Samuels 2002, p. 246).

Esta primera versión del primitivismo torna implausible la satisfacción de la condición de relevancia evidencial: ¿En qué medida los fenómenos empíricos de la pobreza del estímulo, o de adquisición temprana, ofrecerían evidencia a favor de una tesis metateórica acerca del rol que determinados conceptos desempeñan en psicología cognitiva? Simplemente no parece ser la clase de evidencia relevante para este tipo de cuestiones metateóricas. No sin razón, Samuels (2007) reemplaza esta primera presentación por una versión psicológica del primitivismo, según la cual una estructura es innata si, siendo postulada por una teoría psicológica correcta, no es adquirida mediante ningún proceso psicológico. Según esta versión, el énfasis no está puesto en la línea divisoria entre teorías psicológicas y teorías más básicas, sino en la línea divisoria entre procesos psicológicos y no psicológicos de adquisición. Si bien Samuels no ofrece ninguna aclaración acerca de la distinción entre estos tipos de procesos (algo que es fuertemente criticado por Mallon y Weinberg 2006), está claro que los procesos psicológicos paradigmáticos que tiene en mente son procesos de aprendizaje tales como la inducción o el testeo de hipótesis.

La dificultad principal que enfrenta la versión psicológica del primitivismo es el llamado "problema de la sobregeneralización" (Samuels 2002, p. 258), que está vinculado con la satisfacción del requisito de adecuación extensional. Según el primitivismo, un rasgo cognitivo es innato sólo si no es adquirido mediante ningún proceso psicológico. Ahora bien, considérese la clase de aquellas enfermedades que, si bien tienen efectos psicológicos específicos, los tienen por procesos casuales que no pueden ser descriptos en términos 
psicológicos. Por ejemplo, las alucinaciones perceptivas producidas por la fiebre de Ross River (una enfermedad tropical transmitida por ciertos mosquitos) son ciertamente rasgos cognitivos adquiridos mediante procesos no psicológicos; sin embargo, no las consideraríamos innatas (ibídem). O bien considérense los casos de lesiones cerebrales que producen efectos cognitivos específicos. Una persona involucrada en un accidente de tránsito puede padecer un daño cerebral tal que cause pérdida de memoria, o la presencia de imágenes ilusorias en el campo visual (ibidem). Sin embargo, estas estructuras, aunque adquiridas por procesos no cognitivos, no serían innatas. Samuels se propone superar estos contraejemplos introduciendo una condición de normalidad en su análisis:

Condición de normalidad: Una estructura cognitiva $S$ poseída por un organismo $O$ es innata sólo si $O$ adquiriría $S$ en el curso normal del desarrollo.

La introducción de esta condición permite excluir de la clase de las estructuras innatas a aquellas producidas por enfermedades adquiridas o por lesiones cerebrales. No se trataría de instancias en las cuales se adquieren estructuras innatas, pues forman parte de cursos anormales de desarrollo. Son, más bien, instancias en las que factores accidentales del ambiente alteran el curso estándar del desarrollo (Samuels 2002, p. 259). La introducción de esta condición de normalidad pone de manifiesto las limitaciones del enfoque primitivista. Se trata, en un sentido claro, de una propuesta muy poco informativa acerca de las condiciones que debe cumplir un rasgo para ser innato, pues ¿en qué consiste el curso normal del desarrollo de un organismo? Samuels no ofrece una elucidación de la noción de desarrollo estándar o normal de un organismo. Ofrecer tal análisis implicaría abandonar el ámbito "autónomo" de la psicología cognitiva e involucrarse con las teorías entrecampos que vinculan las estructuras postuladas desde las 
ciencias cognitivas con los modelos de desarrollo provenientes de ciencias más básicas. En la medida en que Samuels no ofrece un análisis del desarrollo estándar de un organismo, su enfoque resulta poco esclarecedor, y corre el peligro de analizar lo oscuro por lo más oscuro. Según mi parecer, esta oscuridad se disipa una vez que tenemos en cuenta que la existencia de un baüplan, i. e. un "plan corporal" en el desarrollo de un organismo, forma parte del explanandum de las teorías y los modelos científicos en genética del desarrollo.

Esta incompleción de los enfoques autonomistas acerca del innatismo también puede verse si atendemos a la evidencia empírica proveniente de déficits cognitivos específicos asociados a alteraciones genéticas específicas. En el caso del lenguaje, este tipo de evidencia aparece claramente en los estudios realizados sobre un subtipo de SLI, que involucra una alteración severa en el desarrollo de capacidades morfosintácticas (Gopnik 1990; 1997). Este déficit específico fue diagnosticado en un tercio de los miembros de una familia inglesa, los $\mathrm{KE}$, a lo largo de tres generaciones, y en otro paciente no relacionado con la familia. Gopnik (1997) sostiene que los problemas en el desarrollo lingüístico de los miembros afectados de la familia KE se basan en un daño en el desarrollo de capacidades específicamente sintácticas, tales como el uso de marcadores de tiempo, género y número. Ahora bien, lo interesante es que el déficit que afecta a la familia KE sigue un patrón hereditario claramente mendeliano, lo cual sugiere que la enfermedad puede estar causada por una mutación de un único gen dominante. Este patrón hereditario es común a miles de enfermedades humanas que se sabe que están causadas por cambios en un único gen (Marcus y Fisher 2003). Mediante el estudio del ADN de los miembros de la familia, Fisher y sus colegas fueron capaces de rastrear la mutación específica hasta una alteración de un único polipéptido de la secuencia del gen regulador FOXP2 (Lai et alia 2001). Desde el punto de vista genético, no se requiere nada más que la alteración en el gen FOXP2 para que se manifieste la mutación (dadas 
ciertas condiciones ambientales), lo cual sugiere fuertemente que nos encontramos frente a lo que, en términos de Ghering (2005), sería un gen de control maestro, esto es, un gen cuya función es desencadenar la transcripción de (generalmente, miles de) otros genes asociados al desarrollo de estructuras fenotípicas específicas.

Hay psicólogos y filósofos que, siguiendo la línea de estudios de Vargha-Khadem, ponen en cuestión el carácter específicamente gramatical del déficit que afecta a la familia KE, al acentuar las dificultades motoras de estos individuos para realizar movimientos coordinados complejos de boca y rostro, lo cual les dificultaría el habla (Vargha-Khadem y Passingam 1990; Cowie 1999). Otros psicólogos, como Paula Tallal (Tallal y Curtiss 1997), sostienen que la mutación en FOXP2 es responsable, no de una deficiencia específica en las habilidades morfosintácticas, sino de una deficiencia en el procesamiento del input auditivo durante el desarrollo temprano de los individuos. Estos cuestionamientos son relevantes para el debate entre nativistas y empiristas acerca del lenguaje, pues señalan que, aun cuando el desarrollo del SLI tiene un fuerte componente genético, el daño no es tan selectivo o específico como lo plantea Gopnik, sino que afecta otras capacidades que, aunque relevantes para el posterior desarrollo del lenguaje, no forman parte de un módulo específico del dominio lingüístico. La estrategia de explicación nativista adoptada por Gopnik es compleja (y arriesgada) y requiere argumentar a favor de varias hipótesis polémicas: (i) que el "perfil funcional" de los miembros de la familia KE es similar o generalizable a la mayoría de los individuos afectados por SLI; (ii) que los sujetos presentan un déficit específico y acotado a las habilidades morfosintácticas; (iii) que la mutación en FOXP2 "controla” el desarrollo del síndrome y no sólo el desarrollo de otras capacidades que, siendo precursoras del lenguaje, afecten la aparición de este último. El éxito de esta estrategia nativista de explicación es, por supuesto, una cuestión empírica. Lo único que me interesa destacar aquí, en relación a los enfoques autonomistas del 
innatismo, es que la propia investigación en psicología cognitiva se orienta a establecer vínculos interdisciplinarios con ciencias más básicas como la biología del desarrollo y la genética molecular. La evidencia de déficits cognitivos específicos y hereditarios, aunque compleja y revocable, no apunta a destacar (meramente) el carácter "no psicológico" del proceso de adquisición, sino a la influencia determinante de factores genéticos en el desarrollo de ciertos rasgos cognitivos.

\section{Innatismo, canalización ambiental y control genético}

En esta sección argumento, en primer lugar, que la mejor manera de concebir la propuesta biologicista más solida disponible en la bibliografía filosófica -a saber, la propuesta del innatismo como canalización ambiental de Ariew (1999; 2006)- es en términos del control genético sobre el desarrollo de una estructura dada. En segundo lugar, sostengo que el concepto de control genético se encuentra perfectamente atrincherado en las teorías y modelos de la biología del desarrollo y que permite satisfacer, de manera aceptable, los requisitos establecidos en la sección 2. Es importante aclarar que no pretendo estar ofreciendo condiciones necesarias y suficientes para el concepto de lo innato en ciencias cognitivas. Sólo contamos, desde el punto de vista filosófico, con criterios experimentales para caracterizar el concepto de control genético en biología del desarrollo. Por lo tanto, aunque considero que mi propuesta en términos de control genético establece condiciones necesarias para un análisis de lo innato, no ofrece condiciones suficientes: para alcanzar estas últimas, se requieren mayores desarrollos empíricos y conceptuales. En este sentido, lo que ofrezco es una elucidación parcial -aunque aceptable a la luz de los requisitos establecidos- del concepto de lo innato en ciencias cognitivas.

Según Ariew (1999), una estructura es innata en la medida en que el curso de desarrollo de esa estructura, en los individuos que Manuscrito - Rev. Int. Fil., Campinas, v. 36, n. 2, p. 263-310, jul.-dez. 2013. 
poseen una instancia del genotipo correspondiente, está canalizado respecto del ambiente; y el grado en el cual un curso de desarrollo está canalizado respecto del ambiente es aquel en el cual el desarrollo de la estructura en cuestión es insensible al espacio de las posibles condiciones ambientales iniciales y de las fluctuaciones ambientales que puedan ocurrir durante el desarrollo.

Ariew toma la noción de canalización de un modelo teórico de la epigénesis de los sistemas en desarrollo propuesto por Waddington (1957). El hecho que interesaba a Waddington es el siguiente: los organismos, en estado salvaje, tienden a alcanzar, como estadio final del desarrollo, sólo un número pequeño y determinado de tipos de formas corporales, a pesar de la variación tanto ambiental como genética a la que están sometidos durante el curso del desarrollo. Para explicar esta uniformidad fenotípica "atrincherada" frente a la variación genética y ambiental, Waddington propuso concebir el desarrollo de un organismo según el modelo de un "paisaje epigenético". Este modelo representa el desarrollo de un sistema u organismo como la trayectoria de una bola a través de un sistema de colinas, valles y canales de desarrollo, cada uno de los cuales conduce a un estado fenotípico final diferente. La topografía de la superficie está determinada por el genotipo global del organismo. Una vez que el sistema ingresa en un canal del paisaje epigenético, el desarrollo del estado fenotípico final al que dicho canal conduce se torna prácticamente insensible a cualquier variación ambiental o genética que pueda tener lugar.

Ahora bien, es fundamental tener en cuenta que lo que le interesa a Ariew -a fin de elucidar el concepto de lo innato no es este tipo de canalización respecto de variaciones genéticas y ambientales, sino la canalización del desarrollo de una estructura respecto sólo de factores ambientales. Para entender este segundo tipo de canalización, es necesario que consideremos que algunos de los parámetros que pueden determinar la forma del paisaje epigenético son factores ambientales (Griffiths y Machery 2008). Un estado fenotípico final está 
canalizado respecto del entorno sólo si aquellas características del paisaje que controlan el desarrollo hacia ese estado final son relativamente insensibles a la variación de los parámetros ambientales. Como señala Ariew (1999), el concepto de canalización denota un proceso en el cual el producto del desarrollo se manifiesta a pesar de las posibles perturbaciones que puedan ocurrir en el entorno de desarrollo.

Resulta esclarecedor presentar la propuesta de Ariew en comparación con la elucidación de lo innato en términos de invariancia ambiental de Sober (1998). Según Sober, una estructura es innata para un genotipo dado si y sólo si esa estructura se manifiesta en un amplio rango de entornos de desarrollo. Así descripta, la posición de Sober asimila el concepto de lo innato con una de las fuentes de evidencia que menciono al tratar el requisito de relevancia evidencial. Ariew toma nota de esta confusión en el planteo de Sober, y afirma que la invariancia sólo puede ser un índice falible de innatismo, pero nunca su elucidación. Que una estructura se manifieste en un amplio rango de entornos indica que, posiblemente, el curso de desarrollo de tal estructura está canalizado, pero no es condición necesaria (ni suficiente) para que lo esté. La propuesta de invariancia es inadecuada en tanto no reconoce que lo fundamental para las adscripciones de innatismo es el cómo del desarrollo de una estructura, y que, en este sentido, dicha estructura puede emerger de modo invariante por, al menos, dos razones distintas: debido a un proceso de desarrollo que es sensible a factores del entorno (por tanto, no canalizado), siendo estos últimos invariantes en el entorno de desarrollo normal del organismo; o debido al control genético estricto sobre el desarrollo, de modo que el resultado del proceso está fuertemente canalizado respecto de las variaciones del entorno. Sólo en los casos en los cuales la invariancia en la manifestación de una estructura sea índice de procesos de desarrollo bajo control genético estricto podrá considerarse que dicha estructura es innata. 
El concepto de canalización tout court es un concepto disposicional que, como tal, no pretende comprometerse con la especificación de ninguno de los mecanismos que subyacen al grado de robustez del curso de desarrollo de una estructura (Wimsatt 1999). Ariew, en cambio, al poner el énfasis explicativo en la idea de canalización ambiental, se ve obligado a expedirse respecto de la cuestión de los mecanismos que subyacen a la insensibilidad a los factores ambientales y, por lo tanto, vincula conceptualmente la noción de canalización con la idea de un curso de desarrollo bajo control genético. ${ }^{7}$ Sin embargo, el autor no ofrece mayores detalles acerca de lo que entiende por control genético sobre el desarrollo. En ausencia de tales detalles, su propuesta, aunque bien orientada, permanece incompleta. ¿Constituye el concepto de control genético una opción filosóficamente coherente y científicamente respetable? En lo que resta de esta sección me propongo complementar el enfoque biologicista de Ariew mediante un análisis parcial y provisorio del concepto de control genético.

Casi todas las células del cuerpo contienen una copia completa del genoma de la especie; lo crucial para el desarrollo es, más bien, cuáles genes se expresan, y cuáles no, en cada región y en cada momento. Entre otros factores, la expresión de un gen determinado viene dada por la presencia de proteínas regulatorias específicas que

7 Podría objetarse que esta lectura de la propuesta de Ariew equivale a afirmar lo siguiente: una estructura (i.e. una capacidad cognitiva) de un organismo $O$ es innata si es, simplemente, el resultado del desarrollo ontogenético de $O$, pues podría pensarse que todo rasgo filogenético resultado de la ontogenia se halla bajo control genético estricto. Sin embargo, considero que la noción misma de "paisaje epigenético" de Waddington (1957) pretende poner en evidencia, justamente, que existen diversas variantes o tipos de desarrollo ontogenético, de los cuales - si hemos de creer a Ariew (1999) sólo algunos están vinculados con el desarrollo de rasgos innatos, a saber, aquellos que están canalizados respecto de factores ambientales y se hallan, por tanto, bajo control genético estricto.

Manuscrito - Rev. Int. Fil., Campinas, v. 36, n. 2, p. 263-310, jul.-dez. 2013. 
interactúen con la región regulatoria del gen para que ésta active o dispare la transcripción de la región estructural y desemboque en la construcción de una determinada proteína. Dichas proteínas regulatorias controlan la expresión de otro gen o de conjuntos de otros genes, cada uno de los cuales puede activar la transcripción de otros, desplegando así una cascada genética dominada por un conjunto (que puede tener un único elemento) de genes reguladores encargados de ensamblar la proteína regulatoria relevante (Marcus 2005). Mediante estas cascadas genéticas, unos (relativamente) pocos genes son capaces, en principio, de dirigir el desarrollo de un conjunto enorme de células y rasgos fenotípicos, entre ellos (presumiblemente) rasgos o estructuras neurofuncionales. Pues bien, sostengo que una capacidad cognitiva $C$ es innata en la medida en que el desarrollo de las estructuras neurofuncionales que subyacen a $C$ se halla bajo control estricto de un conjunto (más o menos amplio) de genes reguladores, que se encuentran al tope de una red genética regulatoria que desemboca, en condiciones normales de desarrollo, en la manifestación de C. ${ }^{8}$ En contraste con otros enfoques centrados en la "determinación genética" de un rasgo, la propuesta en términos de control genético no se compromete con la tesis de que el desarrollo de un rasgo pueda ser el resultado de la acción de factores genéticos solamente. En este sentido, el enfoque propuesto no viola la tesis interaccionista, según la cual todo rasgo biológico es el resultado de la acción conjunta de factores genéticos y ambientales.

Entiendo por redes genéticas regulatorias aquellas secuencias precableadas de código genético regulatorio cuyo rol funcional consiste

${ }^{8}$ No debe confundirse esta condición de normalidad con la noción de "plan de desarrollo normal" que aparece en el análisis primitivista de Samuels (2002). De hecho, la existencia misma de un plan estándar de desarrollo es explicado, en el nivel de la genética del desarrollo, mediante la postulación de redes genéticas regulatorias que controlen el curso de la ontogénesis, insensibilizándolo a la mayoría de las contingencias ambientales.

Manuscrito - Rev. Int. Fil., Campinas, v. 36, n. 2, p. 263-310, jul.-dez. 2013. 
en especificar los conjuntos de genes que deben ser expresados en patrones temporales y espaciales específicos (Davidson y Levine 2005, p. 4935). Una de las maneras más simples (pero no la única) de representar las relaciones en una red regulatoria es mediante un grafo dirigido compuesto de nodos y arcos, en los cuales un nodo representa un gen (o el producto de un gen) mientras que un arco conectando dos nodos indica la existencia de una interacción entre los genes. Una representación esquemática de este tipo permite capturar dos aspectos de la regulación genética: por un lado, representa los patrones de interacción entre los genes; por otro lado, captura los tipos de interacción que pueden presentar (por ejemplo, si se trata de una activación o de una represión de la transcripción de un gen regulador) (Goutsias y Lee 2007). Estos modelos de las redes genéticas regulatorias presentan, a su vez, dos propiedades representacionales relevantes: la compleción y la autenticación. Un modelo es idealmente completo sólo si representa todos aquellos genes reguladores que efectivamente están involucrados en un proceso de desarrollo. La compleción puede ser evaluada sólo en la medida en que disponemos de información acerca de la secuencia genómica completa del organismo. Un modelo es idealmente auténtico sólo si representa todas aquellas interacciones entre módulos reguladores que están codificadas en la secuencia genética. Según Levine y Davidson (2005), la única manera de autenticar una red genética regulatoria es mediante la manipulación experimental directa de los módulos regulatorios individuales.

Hasta donde alcanza mi conocimiento, no disponemos actualmente de análisis conceptuales más precisos acerca de la idea de control del desarrollo mediante una red genética regulatoria. Una notable excepción es Woodward (2006, p. 41, 46), quien sugiere (aunque no lo desarrolla sistemáticamente) analizar el concepto de control genético en términos de insensibilidad causal. Según este autor, un rasgo fenotípico se haya bajo control genético en la medida en que existe una relación relativamente insensible que va de algún rasgo del 
genotipo hacia ese aspecto del fenotipo - esto es, una relación estable a través de varios entornos diferentes. Si bien constituye un antecedente importante, lo cierto es que analizar el concepto de control genético en los términos que Woodward propone nos devuelve inmediatamente a la idea de canalización ambiental de Ariew.

Una salida plausible, aunque provisoria, consiste en reinterpretar ciertas "definiciones" o "condiciones necesarias y suficientes" que aparecen en la bibliografía sobre redes genéticas regulatorias en biología del desarrollo como criterios operacionales para la aplicación del concepto de control genético. Dichos criterios permitirían ofrecer ejemplares paradigmáticos de aplicación de control genético que ilustren el grado de atrincheramiento teórico del concepto en biología del desarrollo, aun cuando no contemos todavía con una caracterización perspicua desde el punto de vista filosófico.

Puede resultar un buen punto de partida la siguiente "definición" de control genético, propuesta desde el campo de la genética del desarrollo por Baker, Taylor y Hall:

En genética del desarrollo, se dice que un gen controla un proceso de desarrollo si (...) el funcionamiento de ese gen es necesario y suficiente para dirigir el desarrollo de un estado final particular. La necesidad se establece mostrando que la ausencia de la función del gen lleva a un fracaso en el acaecimiento del proceso de desarrollo. La suficiencia se establece mostrando que la expresión del gen en células en las cuales se expresa normalmente puede inducir en esas células el patrón de desarrollo que normalmente especifica. (Baker, Taylor y Hall 2001, p. 14)

Las condiciones necesarias y suficientes para el control genético de un rasgo, reinterpretadas como criterios operacionales, nos permiten presentar ciertos ejemplares paradigmáticos de aplicación del concepto en genética del desarrollo. Si la ausencia de la función de un determinado gen (o conjunto de genes) impide el desarrollo y la manifestación de un rasgo y la expresión de ese gen (o conjunto de genes) puede inducir, en condiciones normales, el patrón de desarrollo 
del rasgo mencionado, entonces se puede decir que ese gen controla el desarrollo del rasgo. Consideremos, en primer lugar, el comportamiento masculino de cortejo de la Drosophila (Greenspan 1995; Baker, Taylor y Hall 2001; Marcus 2004). El comportamiento en cuestión es típico de la especie, sigue patrones de desarrollo preestablecidos y no requiere experiencia previa ni con hembras ni con otros machos de la especie. Cuando un macho corteja por primera vez a una hembra, despliega una serie estereotipada de acciones, entre ellas: orientarse hacia y perseguir a la hembra, tocarla con sus patas delanteras, producir un canto de apareamiento específico de la especie mediante la vibración de sus alas, lamer los genitales de la hembra y, finalmente, enroscar su abdomen para intentar la copulación. Una serie de estudios (reseñados en Greenspan 1995) muestran que existen áreas del sistema nervioso central de la mosca que se corresponden específicamente con algunas de las etapas de la rutina del cortejo. Lo que resulta impactante es que "una única jerarquía de genes reguladores controla todos los aspectos de la diferenciación sexual de las moscas" (Baker, Taylor y Hall 2001, p. 17) y que, especialmente la rama de la jerarquía a cuyo tope se encuentra el gen fru especifica el desarrollo de las áreas específicas del sistema nervioso central responsables del comportamiento sexual de la mosca. No sólo aquellos individuos que poseen mutaciones en el gen fru no logran desarrollar prácticamente ninguna de las etapas del comportamiento del cortejo, sino que también es posible mostrar que las mutaciones en el gen fru no resultan en déficits conductuales de dominio general.

En segundo lugar, consideremos los experimentos sobre el control genético de desarrollo del ojo en la Drosophila realizados por Gehring y sus colegas. Estos investigadores lograron activar artificialmente el gen PAX6, que se creía estaba involucrado en el desarrollo del ojo, en otros lugares en los cuales normalmente no se desarrollan ojos, como las antenas o las patas de la mosca. Cuando PAX6 se activa en estos lugares inusuales, la mosca desarrolla un ojo 
extra en esas áreas. Esta inducción artificial de ojos ectópicos llevó a Gehring a describir a PAX6 como un "gen de control maestro al tope de una cascada de genes que llevan a la morfogénesis del ojo y que este interruptor maestro puede iniciar el desarrollo del ojo tanto en insectos como en mamíferos" (2005, p. 172).

Una vez que identificamos los criterios operacionales para la aplicación del concepto de control genético en biología y que presentamos algunos ejemplares paradigmáticos en la aplicación del concepto, cabe preguntarse lo siguiente: ¿En qué medida una elucidación de lo innato en términos de control genético satisface las condiciones de adecuación previamente establecidas?

La propuesta de elucidación que defiendo satisface plenamente la condición de adecuación extensional, pues permite incorporar en la extensión del concepto todos los ejemplares paradigmáticos de estructuras innatas, no sólo de las ciencias cognitivas sino también aquellos de otros campos de la biología, como los vistos del desarrollo del ojo y de la conducta de apareamiento en la Drosophila, y otros (que aquí sólo puedo mencionar) tales como los ciclos circadianos y la conducta impulsiva en los ratones (Takahashi et alia 1994, Brunner y Hen 1997). Así, la elucidación en términos de control genético permite incluir en la extensión del concepto el estado inicial de la GU chomskiana (véase la sección 6), las operaciones y la información de los módulos periféricos o perceptivos que, según Fodor (1998a, p.128) están "genéticamente preprogramada[s]", y también permite incluir otros módulos no perceptivos como el módulo de teoría de la mente, cuyo carácter esencial, según Scholl y Leslie (1999, p. 134) "viene dado como parte de nuestro equipamiento genético".

En lo que concierne al vínculo entre el desarrollo de los módulos perceptivos y el control genético, Fodor (1983, p. 142) señala que "los mecanismos neurales destinados al análisis de las entradas se desarrollan conforme a unas pautas específicas determinadas de modo endógeno y activadas por el influjo de la estimulación ambiental", siendo que esta 
idea de determinación endógena es ventajosamente analizable, como he argumentado, en términos de canalización respecto del ambiente y, particularmente, en términos de control genético sobre el desarrollo. Actualmente, en muy pocos casos contamos con las "teorías entrecampos" (Darden \& Maull 1977) necesarias entre la psicología cognitiva, las neurociencias y la biología del desarrollo como para adelantar una descripción de los mecanismos moleculares que regulan el desarrollo de una estructura cognitiva compleja, como puede ser un módulo perceptivo. Al igual que en el caso del lenguaje (que presenté en la sección 4) la principal evidencia del control genético sobre el desarrollo de estos mecanismos perceptivos proviene de los déficits cognitivos hereditarios asociados a alteraciones genéticas específicas. Cabe mencionar aquí el caso del módulo perceptivo de reconocimiento de rostros. Desde hace más de veinte años contamos con modelos computacionales en psicología cognitiva que describen cómo puede llevarse a cabo esta tarea de detección perceptiva (Bruce y Young 1986). Se sabe, además, que ciertas poblaciones neuronales de la corteza ínferotemporal responden específicamente a estímulos faciales y que las lesiones en esa región del cerebro causan déficits específicos en el reconocimiento de rostros (Kandel et alia 2000). Al conjunto de dichos déficits (sean causados por lesiones o hereditarios) se los denomina, genéricamente, prosopagnosias. Tal como señalan Grüter et alia (2008), la prosopagnosia hereditaria es el primer déficit de ese tipo que ha sido identificado en el sistema central de la visión, y por tanto es de especial interés para nuestro estudio. Todos los linajes estudiados afectados por esta patología concuerdan con un tipo de herencia autosómico dominante, lo cual indica claramente que este tipo de prosopagnosia "puede estar causado por una única mutación en uno o más genes (mutación puntual)", aunque "el gen responsable aún no ha sido identificado" (Grüter et alia 2008, p. 88). El patrón de explicación en este caso es el mismo que hemos visto en el caso del SLI y la mutación en el gen FOXP2. 
Respecto del requisito de relevancia evidencial, mi propuesta permite que todas las fuentes de evidencia relacionadas con este requisito (reseñadas en la sección 2) resulten atinentes para el establecimiento de una hipótesis o teoría nativista. En primer lugar, los fenómenos de pobreza del estímulo (así como los fenómenos de adquisición temprana), en la medida en que sugieren la imposibilidad del aprendizaje, ofrecen evidencia indirecta en apoyo de una explicación nativista del desarrollo, que descienda un nivel y se plantee, en última instancia, en términos de crecimiento biológico. Una vez descartadas las explicaciones de la adquisición del rasgo en términos de aprendizaje, es claro que la única (y la mejor) opción disponible es apelar a una explicación en términos de "crecimiento" del rasgo, esto es, en términos de un curso de desarrollo controlado genéticamente. En el caso particular de la adquisición del lenguaje, considero que el APE chomskiano se encuentra estructurado en dos tramos. El primer tramo puede pensarse como un argumento de la forma modus tollens en contra del empirismo respecto del "aprendizaje" del lenguaje. Si el empirismo es verdadero, entonces los niños enfrentan exitosamente la tarea de adquisición del lenguaje equipados sólo con mecanismos de aprendizaje de dominio general. Esto sólo sería posible si la evidencia disponible en los datos lingüísticos primarios $(d l p)$ fuese lo suficientemente rica como para guiar al aprendiz entre los diferentes conjuntos alternativos de principios lingüísticos incompatibles entre sí. Sin embargo, existe un número indefinido de conjuntos de principios incompatibles entre sí pero adecuados a la escasa evidencia disponible en los $d l p$. Por lo tanto, el empirismo acerca de la adquisición del lenguaje es falso. El segundo tramo del APE puede pensarse como una variante compleja de inferencia a la mejor explicación que busca complementar la conclusión negativa del primer tramo con una propuesta positiva acerca de cómo se adquiere una lengua. Considero que este segundo tramo puede reconstruirse como la conjunción de un argumento de parsimonia con un argumento empírico del tipo de “¿Qué más podría ser?” (van 
Gelder, 1995). Respecto del "principio de parsimonia", presupuesto por Chomsky, no es otra cosa que la expresión de su naturalismo metodológico: si se encarase el problema de la adquisición de la lengua de manera naturalista y tal como se encararía el problema respecto del desarrollo de cualquier otro rasgo biológico, entonces la mejor explicación (de hecho, la única) disponible consiste en considerar la adquisición del lenguaje como un caso de crecimiento biológico. Considérese la siguiente cita de Chomsky:

Quisiera sugerir que en ciertos respectos fundamentales realmente no aprendemos la lengua; más bien la gramática crece dentro de la mente. Cuando alcanzan su forma madura el corazón, el sistema visual u otros órganos corporales, hablamos de crecimiento más que de aprendizaje. ¿Existen propiedades fundamentales que distinguen el desarrollo de los órganos físicos y el lenguaje que nos conduzcan a distinguirlos como desarrollo en un caso y aprendizaje en el otro? Tal vez sí, pero no es obvio que así sea. Parece que en ambos casos la estructura final que se alcanza y su integración al sistema complejo de órganos están predeterminados en gran parte por nuestro programa genético..." (1980, p. 143)

De esta manera, en contra de aquellos que creen que el APE sólo muestra que no hay explicación psicológica, y que no muestra que la explicación sea "biológica", esta reconstrucción del APE está en consonancia con la conclusión chomskiana, producto de una inferencia a la mejor explicación, que conduce a entender el innatismo en términos biológicos. Pero, ¿por qué toda instancia de APE mostraría o sería evidencia de, específicamente, un fenómeno de control genético? Por supuesto, podrían existir otras elucidaciones en términos más directos de "causación genética", pero considero que el análisis en términos de control genético comparte todas las ventajas que puedan tener dichas elucidaciones alternativas (en la medida en que comparten el reduccionismo), al mismo tiempo que evita sus dificultades (por ejemplo, cierta concepción internalista del desarrollo, véase la sección 6). En otras palabras: la manera más clara de entender que la 
explicación del desarrollo cognitivo sea "biológica" es en términos del concepto de control genético tal como se lo utiliza en biología del desarrollo.

En segundo lugar, el hecho de que una estructura se manifiesta en un amplio rango de entornos puede constituir evidencia en apoyo al innatismo, en la medida en que sugiere robustez en el desarrollo de dicha estructura -robustez cuya mejor explicación parece apelar a mecanismos de control genético sobre el desarrollo. En tercer lugar, la presencia de un período crítico de adquisición sugiere que el desarrollo de la estructura en cuestión responde a un calendario biológico preestablecido y que, por lo tanto, no está sujeta a las contingencias de la experiencia sino, nuevamente, a una necesidad biológica de desarrollo. Por último, la mayor fortaleza de esta elucidación radica en que es la única posición que permite tornar relevante, de un modo no trivial, para el establecimiento de tesis nativistas, a la evidencia proveniente de déficits del desarrollo hereditarios y específicos asociados a alteraciones genéticas locales, como parece ser el caso del subtipo de daño selectivo del lenguaje estudiado por Gopnik (1990; 1997) y las mutaciones en el gen regulador maestro FOXP2 reseñadas en Marcus y Fisher (2003).

\section{Objeciones y Respuestas}

En primer lugar, hemos visto que los principales referentes del nativismo en ciencias cognitivas vinculan explícitamente el uso del concepto en sus teorías con los usos del concepto en biología. La cita chomskiana más relevante para nuestra causa no proviene en este caso de Chomsky, sino del lingüista Lyle Jenkins, cuando afirma que:

El estudio de los principios y parámetros en el lenguaje es muy similar al que emprenden los biólogos del desarrollo, quienes tratan de encontrar los mecanismos de control genético u otros mecanismos celulares en un esfuerzo por explicar la diferenciación del cigoto hacia su estado final (...) A pesar de que el estudio del problema del 
crecimiento del lenguaje se encuentra en sus etapas iniciales y está basado en parte en el estudio de propiedades abstractas formales, como lo estuvo la genética mendeliana inicialmente, el fin último es una elucidación de los mecanismos que subyacen al lenguaje. (Jenkins 2000, pp. 77 y 78 )

A continuación, Jenkins advierte que “el lenguaje humano no está enteramente preprogramado genéticamente" (2000, p. 78). Esta observación podría pensarse que afecta a nuestra elucidación en términos de control genético sobre el desarrollo. Sin embargo, la respuesta a esta objeción ya está disponible en la bibliografía filosófica sobre la cuestión del innatismo: consiste en diferenciar entre la adscripción de innatismo para el caso del estado inicial de la facultad del lenguaje y la adscripción para el caso de las variaciones sintácticas que distinguen las lenguas particulares, como el español y el inglés; o, en otros términos, entre la GU y las diferentes lenguas-I. En particular, mientras el estado inicial que constituye la GU está altamente canalizado respecto de los entornos en los cuales se desarrolla (y, por tanto, se halla bajo control genético, y es innato), los diferentes estados finales que alcanza la facultad del lenguaje son sumamente sensibles a claves ambientales presentes en los datos lingüísticos primarios y no son, en consecuencia, innatos.

En segundo lugar, quisiera tratar una cuestión que muchos considerarían como un problema central e insalvable para mi propuesta, y que también está vinculado con la satisfacción del requisito de adecuación extensional. Se piensa que, a la fijación de recuerdos particulares en la memoria de largo plazo (en el nivel cognitivo), subyace (en el nivel neurofisiológico) un fenómeno neuronal ampliamente estudiado: la potenciación de largo plazo (o LTP), que involucra cambios estructurales importantes en una neurona postsináptica (Kandel et alia 2000, p. 36). Este fenómeno involucra la activación de genes reguladores, que forman parte de una red genética regulatoria, en el núcleo de la neurona postsináptica (nivel molecular). La transcripción de estos genes es "dependiente de la actividad 
neuronal", esto es: se da en respuesta a una gran variedad de estímulos ambientales que van desde las experiencias visuales y el condicionamiento hasta el abuso de drogas (Greer y Greenberg 2008, p. 846). Pues bien, el problema para mi propuesta radica en que la fijación de recuerdos particulares en la memoria de largo plazo (en tanto parte del funcionamiento normal de un cerebro adulto) quedaría catalogada como innata, pues involucra centralmente el despliegue de una red genética regulatoria. Sin embargo, parece una opinión razonable negar que un recuerdo particular sea innato.

Para comenzar a responder esta objeción, conviene notar que el proceso de fijación de recuerdos particulares en la memoria de largo plazo no es un proceso que presente un alto grado de canalización respecto del ambiente. Rasgos tales como los recuerdos perceptivos y las creencias particulares son rasgos cuyo desarrollo es sensible, de manera crucial, a la presencia de factores específicos del ambiente. Aun cuando haya un componente genético involucrado en la adquisición de recuerdos perceptivos, podría afirmarse que el programa de expresión genética involucrado en la fijación de recuerdos se halla bajo control del estímulo ambiental, tal como sostiene el propio Greenberg en un reciente artículo sobre el tema:

Una cantidad sustancial de datos indica que el imput sensorial en la vida temprana controla un programa de expresión genética que es esencial para transducir la experiencia sensible en cambios de largo plazo en el desarrollo y la función del cerebro. (West y Greenberg 2011, p. 1; las cursivas son mías)

Esta primera respuesta sólo pone de manifiesto algo que ya era evidente, a saber: que el proceso de fijación de recuerdos particulares, como tal, no se encuentra bajo control genético y que, por tanto, los recuerdos así adquiridos no son innatos. Ahora bien, un posible objetor podría remarcar que, en la medida en que la fijación de recuerdos involucra centralmente la activación de genes reguladores en el contexto de redes genéticas regulatorias, mi propuesta estaría obligada a 
considerar que dichos recuerdos son innatos - afirmación que resulta altamente contraintuitiva. Sin embargo, vale recordar que mi propuesta, tal como la presenté en la sección 5, no se limita a exigir que una red genética meramente "participe" en el desarrollo del rasgo, sino que exige que este último se encuentre bajo el control de la primera. $\mathrm{Si}$ bastase con la participación (central o periférica) de factores genéticos para que un rasgo sea innato, entonces todos los rasgos biológicos que son el producto de la ontogenia serían innatos, tal como se desprende de la tesis interaccionista. En el caso del proceso de fijación de recuerdos particulares y el fenómeno LTP, podría defenderse que cierta red genética regulatoria "controla" efectivamente cierta tramo acotado de las alteraciones en la fuerza de las conexiones sinápticas (p.e. la red asociada al gen Fos; West y Greenberg 2011, p. 4). Sin embargo, es sólo un tramo de un proceso mucho más extenso (jerárquica, temporal y espacialmente) que, considerado de manera global, se halla ciertamente bajo el control de los estímulos sensoriales, en particular, y ambientales, en general. La transcripción genética obviamente controla un tramo del proceso, pero el proceso in toto está regulado por el input sensorial. De allí que se hable de estos procesos de transcripción genética como siendo dependientes de, o regulados por, la actividad neuronal. Aunque hay factores genéticos participando en los procesos moleculares que subyacen a la fijación de recuerdos particulares, no son dichos factores sino los estímulos sensoriales los que controlan el proceso total, y por tanto los recuerdos particulares así adquiridos no son innatos.

En tercer lugar, otras preocupaciones concernientes al concepto de control genético están vinculadas con el argumento de la escasez de genes defendido por Ehrlich (2000). Según este argumento, el número de genes en el genoma humano (unos 30000) es sumamente escaso en relación al número de neuronas en el cerebro humano (que se encuentra en el orden de los billones), por lo que resultaría (matemáticamente) imposible que los primeros determinen o controlen el desarrollo de las segundas. Si el argumento fuera correcto, entonces 
la idea misma de control genético sobre el desarrollo de rasgos cognitivos estaría mal encaminada. El principal problema del argumento de Ehrlich es que presupone una concepción en extremo lineal y simplista de las relaciones entre genes y rasgos, como si existiera una relación uno a uno entre genes y estructuras fenotípicas. En la medida en que los genes no actúan "en el vacío" sino que participan en diversas cascadas genéticas regulatorias, es el caso que muchos genes pueden estar involucrados en el desarrollo de un mismo rasgo y, a la vez, un mismo gen puede intervenir causalmente en el desarrollo de una variedad de estructuras fenotípicas (Marcus 2004; Mameli y Papineau 2006).

En cuarto lugar, Mameli y Papineau (2006) señalan que las cascadas genéticas están inmersas en un determinado contexto intra y extracelular, de modo tal que, en sentido estricto, todos los rasgos fenotípicos de un organismo son generados por cascadas de interacciones gen-entorno, una conclusión cercana a aquellas de los defensores de la teoría de los sistemas en desarrollo (developmental systems theory, TSE, cf. Griffiths y Gray 1994) y que parece cuestionar la distinción tradicional entre rasgos innatos y rasgos adquiridos. Pues bien, me parece que la observación de Mameli y Papineau es aceptable en la medida en que implica simplemente el reconocimiento de la tesis interaccionista (ningún rasgo es el producto de factores genéticos internos solamente, sino que es siempre el producto de la interacción de factores genéticos y ambientales). Por supuesto que ningún nativista, qua defensor de la existencia de control genético sobre determinado rasgo, pretende sostener alguna forma de internalismo que excluya como causalmente irrelevantes al entorno molecular y celular. Que determinados factores (genéticos) controlen el desarrollo de una estructura no implica que no haya otros factores no genéticos participando causalmente en el desarrollo.

Si el concepto de interacción gen-entorno - entendido en el sentido constructivista radical de la TSE - pretende acentuar o enfatizar la 
importancia determinante de los factores no genéticos del contexto molecular y celular para todo proceso de desarrollo, de modo que la existencia misma de los genes dependa de su contexto fenotípico (Stotz 2006, p. 905), entonces la objeción implica un problema para el nativismo tradicionalmente entendido, aunque no para mi elucidación. El concepto de interacción gen-entorno entendido a la manera de la TSE es claramente polémico, y apunta en la dirección de un programa de investigación alternativo al nativista (y al de la genética del desarrollo tradicional) pues, al centrarse en los aspectos holistas de la interacción entre factores genéticos y no genéticos en el desarrollo celular, parece implicar un abandono de la noción de control genético sobre el desarrollo de un rasgo y, por ello mismo, del concepto de lo innato en biología y otras ciencias. Es justamente porque mi elucidación es convenientemente reduccionista que el debate filosófico respecto del concepto mismo de gen en biología molecular puede resultar relevante para el establecimiento o el abandono del nativismo.

\section{7. ¿Qué hemos argumentado?}

En este artículo he intentado defender un enfoque biologicista respecto de la cuestión del innatismo. En la sección 1, ofrecí una caracterización de dicha cuestión en términos de una tarea de elucidación conceptual relativa al concepto de lo innato en ciencias cognitivas y establecí los lineamientos generales de las tres grandes familias de propuestas presentes en la bibliografía filosófica: las propuestas reduccionistas, autonomistas y escépticas En la sección 2, presenté dos condiciones mínimas de adecuación que toda propuesta filosófica debería satisfacer: la condición de adecuación extensional y la de relevancia evidencial. En la sección 3, discutí el enfoque escéptico de Griffiths (2002), poniendo el acento en la necesidad de reconstruir adecuadamente las relaciones evidenciales entre el innatismo y los fenómenos empíricos con los que generalmente se encuentra asociado 
- necesidad que está recogida en mi condición de relevancia evidencial. En la sección 4 argumenté que la propuesta primitivista de Samuels resulta poco informativa e incompleta en la medida en que no ofrece una caracterización del concepto de plan de desarrollo normal de un organismo -noción que sólo puede elucidarse mediante los modelos y los conceptos de la biología del desarrollo. En la sección 5 presenté una versión (provisional y parcial) del enfoque biologicista centrada en el concepto de control genético, que considero que recoge las principales virtudes de la elucidación del innatismo en términos de canalización ambiental de Ariew (2006) y permite satisfacer, de manera relevante, los requisitos de adecuación establecidos. Por último, en la sección 6, respondí algunas de las principales objeciones que podrían oponerse a la elucidación propuesta. Si mis respuestas han sido exitosas, entonces podrá afirmarse que la elucidación de lo innato en ciencias cognitivas en términos de control genético sobre el desarrollo de un rasgo representa una opción viable y prometedora en relación a la cuestión del innatismo.

\section{BIBLIOGRAFÍA}

ARIEW, A. "Innateness is Canalization: in Defense of a Developmental Account of Innateness". En: V. Hardcastle (comp.) (1999), pp. 117-138.

ARIEW; A. "Innateness". En M. Matthen y C. Stevens (eds.) (2006), pp. 1-18.

BAKER, B., TAYLOR, B., HALL, J. “Are complex behaviors specified by dedicated regulatory genes? Reasoning from Drosophila". Cell, vol. 105, pp. 13-24, 2001

BOYD, R. "Realism, anti-foundationalism and the enthusiasm for natural kinds". Philosophical Studies, vol. 61, pp. 127-148, 1991. 
BRUCE, V., y YOUNG, A. "Understanding face recognition". British Journal of Psychology, vol. 77, no. 3, pp. 305-327, 1986.

BRUNNER D y HEN R. "Insights into the neurobiology of impulsive behavior from serotonin receptor knockout mice". Annals Of The New York. Academy Of Sciences, vol. 836, pp. 81-105, 1997.

CAREY, S. y SPELKE, E. "Conocimiento específico de dominio y cambio conceptual”. En L. Hirschfeld y S. Gelman (eds.) (1994), pp. 243-284.

CARRUTHERS, P, LAURENCE, S. Y STICH, S. (Eds.) The Innate Mind: Structure and Content. New York: Oxford University Press, 2005.

(Eds.), The Innate Mind: Foundations and the future. New York: Oxford University Press, pp. 17-37, 2007.

COLLINS, J. "Nativism: In Defense of a Biological Understanding". Philosophical Psychology, vol. 18. no. 2, pp. 157-177, 2005.

COWIE, F. What's Within? Nativism Reconsidered. Oxford: Oxford University Press, 1999.

CRAIG, E. (Ed.) The Routledge Encyclopedia of Philosophy, vol. 4, London: Routledge, 1998.

CRAIN, S. y PIETROSKI, P. "Nature, Nurture and Universal Grammar". Linguistics and Philosophy, vol. 24, pp. 139-186, 2001.

CHENEY, D. y SEYFARTH, R. Baboon Metaphysics: The evolution of a social mind. Chicago: University of Chicago Press, 2007.

CHOMSKY, N. Reflections on Language. New York: Pantheon Books, 1975.

. Rules and Representations. Oxford: Basil Blackwell, 1980.

- Language and the Problems of Knowledge. Cambridge, MA: MIT Press, 1988.

- The Minimalist Program. Cambridge, MA: MIT Press, 1995.

. "Three factors in language design". Linguistic Inquiry, vol. 36, no.1, pp.1-22, 2005. 
Reseña de Conducta Verbal de B. F. Skinner. México: UNAM, 2013.

DARDEN, L. y MAULL, N. "Interfield Theories". Philosophy of Science, vol. 44, pp. 43-64, 1977.

DAVIDSON, E. Y LEVINE, M. "Gene regulatory networks". Proceedings of the National Academy of Science, vol. 102, no. 14, p. 4935, 2005.

-. "Properties of developmental gene regulatory networks". Proceedings of the National Academy of Science, vol. 105, no. 51, pp. 20063-20066, 2008.

EHRLICH, P. Human Natures: genes, cultures and the buman prospect. Washington DC, Island Press, 2000.

EZCURDIA, M. “Argumentos a favor del innatismo del lenguaje”. En N. Chomsky (2013), pp. 1-48.

FODOR, J. Modularity of mind. Cambridge: MIT Press, 1983.

- Concepts: Where concepts went wrong. New York: Oxford University Press, 1998a.

. In Critical Condition. Polemical Essays on Cognitive Science and the Philosophy. Cambridge: MIT Press, 1998b.

GEHRING, W. "New Perspectives on Eye Development and the Evolution of Eyes and Photoreceptors". Journal of Heredity, vol. 96, no. 3, pp. 171-184, 2005.

GESCHWIND, D. "Genetics of Autism Spectrum Disorders". Trends in Cognitive Sciences, vol. 15, no. 9, pp. 409-416, 2011.

GODFREY-SMITH, P. "Innateness and Genetic Information". En P. Carruthers, S. Laurence y S. Stich (eds.) (2007), pp. 55-68.

GOPNIK, M. "Genetic basis of a grammar defect". Nature, vol. 347, p. 26, 1990.

- "Language deficits and genetic factors". Trends in Cognitive Science, vol. 1, pp. 5-9, 1997. 
GOPNIK, M y CRAGO, M. "Familial aggregation of a developmental language disorder”, Cognition, vol. 39, pp. 1-50, 1991.

GOTTLIEB, G. "Experiential Canalization of Behavioral Development: Theory". Developmental Psychology, vol. 27, no. 1, 413, 1991.

GOULD, J. y MARLER, P. “Learning by Instinct”. En D. Mock (ed.) (1991), pp. 4-19.

GOUTSIAS, J. y LEE, N. H. "Computational and Experimental Approaches for Modeling Gene Regulatory Networks". Current Pharmacentical Design, vol. 13, pp. 1415-1436, 2007.

GREENSPAN, R. "Understanding the genetic construction of behavior". Scientific American, vol. 272, no. 4, pp. 72-78, 1995.

GREER, P. Y GREENBERG, M. "From Synapse to Nucleus: Calcium-Dependent Gene Transcription in the Control of Synapse Development and Function". Neuron, no. 59, pp. 846860, 2008.

GRIFFITHS, P. "What is Innateness?". The Monist, vol. 85, no. 1, pp. 70-85, 2002.

GRIFFITHS, P., Y GRAY, R. "Developmental Systems and Evolutionary Explanation". Journal of Philosophy, vol. 91, no. 6, pp. 277-304, 1994.

GRIFFITHS, P. Y MACHERY, E. "Innateness, canalisation and 'biologicizing the mind'". Philosophical Psychology, vol. 21, no. 3, pp. 397-414, 2008.

GRÜTER, T., GRÜTER, M, CARBON, C. "Neural and genetic foundations of face recognition and prosopagnosia". Journal of Neuropsychology, no. 2, pp. 79-97, 2008.

HARDCASTLE, V. (comp.) Where Biology meets Psychology: Philosophical Essays. Cambridge, MA: MIT Press, 1999.

HAUSER, M. Moral Minds: How nature designed our sense of right and wrong. New York: Ecco Press, 2006. 
JENKINS, L. Biolinguistics. Exploring the biology of language. Cambridge: Cambridge University Press, 2000.

KANDEL, E., SCHWARTZ, J., JESSELL, TH. Principles of Neural Science. New York: Mc-Graw-Hill, 2000.

KARMILOFF-SMITH, A. "Development itself is the key to understanding developmental disorders". Trends in Cognitive Science, vol. 2, no. 10, pp. 389-398, 1998.

KEIL, F. Concepts, Kinds and Cognitive Development. Cambridge: Bradford Books/MIT Press, 1989.

LAI, C., FISHER S., HURST, J., VARGA-KHADEM, F. Y MONACO, A. "A forkhead-domain gene is mutated in severe speech and language disorder". Nature, vol. 416, pp. 519-23, 2001.

LAURENCE, S. Y MARGOLIS, E. “The Poverty of Stimulus Argument". British Journal of Philosophy of Science, vol. 52, pp. 217276, 2001.

LENNEBERG, E. Biological Foundations of Language. New York: Wiley, 1967.

LEVINE, M. Y DAVIDSON, E. "Gene regulatory networks for development", Proceedings of the National Academy of Science, vol. 102, no. 14, pp. 4936-4942, 2005.

LIPTON, J. Y SPELKE, E. “Origins of Number Sense: Large-Number Discrimination in Human Infants". Psychological Science, vol. 14, no. 5, pp. 396-401, 2003.

LORENZ, K. Evolution and the Modification of Behaviour. Chicago: University of Chicago Press, 1965.

MALLON, R. Y WEINBERG, J. "Innateness as closed-process invariantism”. Philosophy of Science, vol. 73, pp. 323-344, 2006. 
MAMELI, M. Y PAPINEAU, D. "The New Nativism: a commentary on Gary Marcus's The Birth of the Mind'. Biology and Philosophy, vol. 21, no. 4, pp. 559-573, 2006.

MAMELI, M. Y BATESON, P. "Innateness and the sciences". Biology and Philosophy, vol. 22, pp. 155-188, 2006.

MARCUS, G. The Birth of The Mind: How a Tiny Number of Genes Creates the Complexities of Human Thought. New York: Basic Books, 2004. "What developmental biology can tell us about innateness". En P. Carruthers, S. Laurence y S. Stich (eds.) (2005), pp. 23756.

MARCUS, G., Y FISHER, S. "FOXP2 in focus: what can genes tell us about speech and language?". Trends in Cognitive Science, vol. 7, no. 6, pp. 257-262, 2003.

MARR, D. Vision. A Computational Investigation into the Human Representation and Processing of Visual Information. San Francisco: Freeman, 1982.

MATTHEN, M. Y STEVENS, C. (eds.) Handbook of the Philosophy of Science. Boston, Elsevier, 2006.

MOCK, D. (ed.) Behavior and Evolution of Birds. San Francisco: Freeman, 1991.

PINKER, S. The Language Instinct, New York: William Morrow \& Co., 1994.

ROTHENBERGER, A. Brain and Behavior in Child Psychiatry, New York: Springer Verlag, 1997.

SAMUELS, R. "Nativism in cognitive science". Mind and Language, vol 17, pp. 233-265, 2002.

. "Is innateness a confused concept?". En P. Carruthers, S. Laurence y S. Stich (eds.) (2007), pp. 17-37.

SCHOLL, B. Y LESLIE, A. "Modularity, Development and 'Theory of Mind"'. Mind and Language, vol. 14, no. 1, pp. 131-153, 1999. 
SOBER, E., "Innate Knowledge". En E. Craig (ed.) (1998), pp. 794797.

SPELKE, E. "Principles of Object Perception". Cognitive Science, vol. 14, pp. 26-56, 1990.

STOTZ, K. 'With 'Genes' Like That, Who Needs an Environment? Postgenomics's Argument for the 'Ontogeny of Information"'. Philosophy of Science, vol. 73, pp. 905-917, 2006.

TALLAL, P., CURTISS, S., "Neurological Basis of Developmental Language Disorders”. En A. Rothenberger (Ed.) (1997), pp. 205213.

TAKAHASHI, J., PINTO, L, VITATERNA, M., "Forward and reverse genetic approaches to behavior in the mouse". Science, Vol. 264, pp. 1724-1733, 1994,

VAN GELDER, T. "What might cognition be, if not computation?”. Journal of Philosophy, Vol. 91, pp. 345-381, 1995.

VARGHA-KHADEM, F. Y PASSINGHAM, R. "Speech and language defects". Nature, vol. 346, p. 226, 1990.

WADDINGTON, C. The strategy of the genes, London: Allen \& Unwin, 1957.

WEST, A. Y GREENBERG, M. "Neuronal Activity-Regulated Gene Transcription in Synapse Development and Cognitive Function". Cold Spring Harbor Perspectives in Biology, disponible online

en: http://cshperspectives.cshlp.org/content/3/6/a005744.full.pdf +html, 2011.

WIMSATT, W. "Generativity, Entrenchment, Evolution and Innateness: Philosophy, Evolutionary Biology, and conceptual foundations of Science”. En V. Hardcastle (Ed.) (1999), pp. 139179 . 
WOODWARD, J. "Sensitive and Insensitive Causation". The Philosophical Review, vol. 115, pp. 1-50, 2006. 